\title{
Research and Publicatgion as Indicators of Quality
}

\author{
Dr. A. Sundaram, \\ Associate Professor, Dept. of Economics, Govt Saiha College, Affiliated to Mizoram University, Saiha, \\ Mizoram, North East India-796901
}

\begin{abstract}
This paper explores the advantages associated with research over disadvantages. This paper emphasis the research should be mandatory for teachers who are guides or prospective guides and research publications should be one of the requirements for promotion.

Although the roles and responsibilities in colleges and universities have significantly changed over the last two decades, graduate faculty and administrators have yet to embrace the reality that the present job market demands skills and experiences of new Ph.D.s that were not required twenty years ago.

Research provides an important learning activity. With some effort, problems faced by teachers and students can be minimized and research output can be improved. To make research a useful and enjoyable exercise, there is a need to change the attitude of students as well as teachers. It is a waste of time trying to reinvent the wheel. Literature should be searched to have an idea on what is already known and how their research will add to current knowledge.

The demands for research and publication on college and universities are explored with a focus on the effect on promotion and tenure. Many administrators feel faculty research is a partner to faculty teaching effectiveness, and thus, if master teaching is the goal, faculty must excel at research. The institution needs academic visibility, and most administrators feel research sets standards and produces role models for colleges and Universities that seek pre-eminence. Ways in which lack of research and publication affect tenure and promotion are discussed. Although the specific criteria for research vary at different institutions, active scholarship is considered essential to the success of all faculty.

This paper is an attempt to examine what is the need for Research and Publication?, What are the importance's of Research and Publication? What is the potential of Research and Publication?, What is the present status of Research and Publication in India and World?, What are the Shortcomings of Research and Publication?, What are the Challenges of research and Publication?, How to improve Research and Publication in India and World?, and Conclusion.
\end{abstract}

Keyword: Higher Education, Academic, faculty, Reward, Promotion, Quality

\section{Introduction:}

Although the roles and responsibilities in colleges and universities have significantly changed over the last two decades, faculty and administrators have yet to embrace the reality that the present job market demands skills and experiences of new Ph.D.s that were not required twenty years ago. Faculty need to be aware that to succeed, the next generation of faculty needs more than research skills and an in-depth knowledge about a narrow specialty in their field.

Academic research has a very simple definition as the intellectual work that creates and publishes new knowledge. The newness of the knowledge distinguishes research from many other intellectual pursuits of high value.

The perceptions of research importance need to be understood and investigated to make an accurate assessment of research importance. Higher education systems and institutions worldwide have undergone extensive reform and change over the past twenty-five years with the agenda of improving quality. A significant feature of this has been the drive to produce systematic evidence of effectiveness and efficiency (Doyle, 2006; Guthrie \& Neumann, 2007; Hayford, 2003).

This paper is an attempt to examine what is the need for Research and Publication?, What are the importance's of Research and Publication? What is the potential of Research and Publication?, What is the present status of Research and Publication in India, World and Mizoram?, What are the Shortcomings of Research and Publication?, What are the Challenges of research and Publication?, How to improve Research and Publication?, and Conclusion.

II. What is the need for Research and Publication?

The literal meaning of research is "an endeavour to discover facts by study or investigation." Undergraduate students need to learn research for a strong foundation. Postgraduate students need research 
methodology for thesis and teachers are guides for conducting their thesis. Practitioners need to understand research, as they have to deal with a variety of cases. Policy makers utilize research for framing policies while administrators take decisions with the help of research outcomes. In short, knowledge of research is needed for all medical professionals and the fields related to medicine.

Teachers also need to publish their research in a peer-reviewed journal as we are fast approaching toward "publish or perish" principle adopted by the western countries.

Teachers should be "role models" for their students in terms of honesty in teaching and conducting ethical research. There are enough evidences to prove that the quality of teaching improves if faculty is oriented toward research. The teachers who have publications are definitely an edge above their rivals when there is competition for promotions.

By doing research, a teacher could have a personal satisfaction of contributing to science and the society, get recognition and appreciation by peers in the profession, acquire a job, get a job promotion, or even retain a job. If teachers keep neglecting research, the day is not far off when our medical institutes will be termed "rehabilitation centers for inefficient teachers.

\section{Importance of Research and Publication:}

Publications are the single most important research outlet of HEIs. However, the complexity of knowledge has led to a diverse range of output formats. The research-based outputs are academic texts, audio visual recordings, computer software and databases, technical drawings, designs or working models, major theatrical works, art exhibitions, patents or plant breeding rights, policy documents or briefs, research or technical reports, legal cases, maps, translations or editing of major works.

During last decade, Indian higher education has witnessed a surge in scientific publications. As the recent guidelines for promotion and recruitment have given wightages to publications, there has been rise in interest among various categories of higher education faculty as well as aspirants for jobs in higher education system in getting their manuscripts published. This has led to sudden rise in number of academic journals, some of which get printed without any sort of editing. The authors become happy when the journal in which their articles are printed has ISSN, although ISSN is not an indicator of quality. Participants become happy, when the publications of conference proceedings, in which their papers are included, have an ISBN, although ISBN is not an indicator of quality.

"Publish or perish" is a phrase coined to describe the pressure in to academia rapidly and continuously publish academic work to sustain or further one's career.

Frequent publication is one of few methods at scholars' disposal to demonstrate academic talent. Successful publications bring attention to scholars and their sponsoring institutions, which can facilitate continued funding and an individual's progress through their field. In popular academic perception, scholars who publish infrequently, or who focus on activities that do not result in publications, such as instructing undergraduates, may find themselves out of debate for available tenure-track positions.

Courses at research universities often incorporate the latest research. Faculty who are engaged in research are more in touch with breaking developments in their field. And they are more likely to include this material-including discoveries too recent to make it into the textbook - in their classes. This makes for more exciting and up-to-date courses that are a whole lot more interesting than courses that are a remix of what's already in the book.

The faculty can be more energized. Faculty at research universities are often making genuine discoveries and receiving recognition for their work. Large salaries, prizes, publications in distinguished journals or at prestigious presses, participation in international conferences or workshops: all of these mean prestige to the professor and, simply, feeling good about him or herself. These good feelings can carry over to the classroom when the professor feels genuine excitement and meaning in sharing with the students what he or she has discovered.

There is the possibility of internships and collaborative research with experts. Studies have shown that some of the best educational experiences for college students take place not in the classroom, but in their interactions with professors outside the classroom, especially in the context of shared research activities. Such collaborative projects provide chances for students to themselves become researchers, and even sometimes coauthors of published papers or co-presenters at conferences, either of which is a major feather in anyone's cap.

the demands for research and publication on college campuses are explored with a focus on the effect on promotion and tenure.

many administrators feel faculty research is a partner to faculty teaching effectiveness, and thus, if master teaching is the goal, faculty must excel at research.

the institution needs academic visibility, and most administrators feel research sets standards and produces role models for colleges that seek pre-eminence. 
The value or importance of research will be linked to elements such as the relevance of the research to problems that exist at the time of the research, and possibly issues that are expected to occur in the future.

The importance of research is linked to the sustainability of research, in that if the research is deemed to be important then presumably its chances of being sustainable would be greatly increased than if it was deemed to be unimportant. A problem exists here however, if the research that is deemed to be unimportant is in fact critical to our understanding of an unforeseen problem in the longer term. As such the perceptions of Performance indicators for assessing and benchmarking research capacity in universities research importance need to be understood and investigated to make an accurate assessment of research importance.

Research and development are essential factors in maintaining U.S. leadership in providing highquality education, healthcare, and quality-of-life. Research and development aid the country in maintaining its economic strength and technological global leadership and are critical to expanding its knowledge base.

The main advantages of Research-oriented universities may attempt to manage the unhealthy aspects of the publish-or-perish practices, but their administrators often argue that some pressure to produce cutting-edge research is necessary to motivate scholars early in their careers to focus on research advancement, and learn to balance its achievement with the other responsibilities of the professorial role.

\section{Potential of Research and Publication:}

Many studies report evidences of positive economic benefits derived from basic research ... In certain areas such as biotechnology, semi-conductor physics, optical communications ..., the impact of basic research is direct while, in other disciplines, the path from discovery to applications is full of surprises.

At best, judgement of the potential of research is an 'inexact science'. Judgements of potential must balance the short-term and the long-term, the mundane and the cataclysmic.

Top researchers can also be top teachers. It's often thought that professors who are serious about their research programs could not care less about teaching and/or are lousy teachers. Instead, many researchers carry their passion for the field into the classroom and are inspirational teachers and role models. Also, professors who do research generally understand the field better than ones who do not, so they can explain the material better to students - especially when it comes to more advanced courses and topics.

\section{Present Status of Research and Publication in India and the world :}

India spends only $1 \%$ of its GDP on research compared to $2.7 \%$ and $3.4 \%$ by the U.S. and Japan. This is just $3.7 \%$ of the global R\&D expenditure and has remained constant at this level for the past five years, while China has increased it from $13 \%$ to $18 \%$ in the same period. Only $4 \%$ of the total R\&D expenditure in our country is from higher educational institutions, putting India the lowest amongst its global peers - China (10\%), Japan (14\%), the U.S. (17\%) and Canada (35\%).

In terms of research productivity, the picture is not encouraging enough. India has 7.8 scientists per 1,000 population compared to 180.66 in Canada, 139.16 in the Russian Federation, 53.13 in Korea and 21.15 in the U.S. Though the number of institutions participating in research in India increased in the last 10 years, $80 \%$ of the publications come only from $10 \%$ of the institutions. In terms of publication output measured by the number of papers published in journals indexed by Web of Science, the Indian share has remained flat under 3\% for the last 10 years. The share of Brazil, South Korea and China has substantially increased during the same period, putting India in the $13^{\text {th }}$ position.

India's research papers were cited on average 3.2 times, putting it in the $119^{\text {th }}$ position out of 149 countries, a little ahead of China (2.9). Among developing countries, India ranks first in publication outputs in four areas - Agriculture, Energy \& Environment, Biology \& Biochemistry and Plant \& Animal Sciences. Though patent filing in India is increasing, it is still behind its Asian peers and significantly less than that of leading international players.

Many countries have undertaken crucial reforms to rejuvenate research in higher education. The inspirational Bayh-Dole Act of 1980 enacted in America unlocked laboratory research in U.S. universities to create an economic impact and the well-being of Americans through the creation of new innovations, companies and products. The average number of annual university patents was 200 before 1980 and jumped to 1,600 during the next decade, out of which $80 \%$ came from federal-funded research projects and universities became the economic growth engine. Campuses began to script success stories that saw the birth of the Internet, Google, pharma products, software and engineering solutions, revolutionising corporate America.

China's spending on research and development has steadily increased to $1.5 \%$ of its GDP and is higher than that of most other developing countries. Since 2000, the number of papers by scholars based in China published in Science Citation Index (SCI)-listed journals has quadrupled. China has outperformed every other nation, with a 64-fold increase in peer-reviewed scientific papers since 1981, with the focus on chemistry and materials science. The Chinese government has urged scientists to publish in reputable English-language journals, offering promotions and other rewards as incentive. China's enormous investment, at a rate above the 
rate of inflation, at all levels of the system — schools to postgraduate research, has been the spine of such a resurgent research boom.

The Indian academic research story needs to be rewritten. There are inherent systemic problems that plague the research environment. Less than $1 \%$ of the total students enrolled in higher education are pursuing $\mathrm{Ph} . \mathrm{D}$. and this is not in pace with the overall growth of students in higher education. The overall quality of doctoral studies in many institutes is questionable. With large faculty vacancies and a poorly qualified faculty, the quality of research in higher education institutes, including the IITs, which have a $20 \%$ vacancy, is diluted.

A survey conducted by the UGC shows that a quarter of the faculty in Indian higher education institutions spends less than five hours per week on research. The quantum of extramural support given by Indian agencies to higher education institutes is insignificant compared to the funding received by other leading institutes abroad. The research budget of Harvard University for the year 2008 was Rs. 250 billion. During this period, the total extramural grant disbursed for R\&D projects to Indian academia was Rs. 12 billion and by the UGC alone was Rs.1.3 billion. Look at the contrast! There is need for an enabling environment for the corporate sector to work with universities on research/commercialisation. Faculty also keep up with developments in their field and consult with government, business, non-profit, and community organizations

\section{India's Publication Share and Rank in World:}

India ranks $12^{\text {th }}$ among the top 20 productive countries in science and technology, with its global publications share of $2.11 \%$ as computed from cumulative world publications data for 1997-2007. The other countries in the top 20 list that contributed world share similar to that of India are Russia, Spain, and Australia (in the range $2.0 \%$ to $2.50 \%$ ). In overall, the global publication shares of the top 20 productive countries in S\&T from $1997-2007$ ranged from $1.03 \%$ to $23.44 \%$. The United States tops the list with its global publication share of $23.44 \%$, and followed far behind are United Kingdom, Japan, China, Germany, and France (their global publication share ranging $4.5 \%$ to $7.4 \%$ ). The countries that rank between $13^{\text {th }}$ and $20^{\text {th }}$ positions are Netherlands, South Korea, Sweden, Switzerland, Taiwan, Brazil, Poland and Belgium with their global publication share ranging $1 \%$ to $1.9 \%$.

\section{Data on Research:}

The databases of Thomson Reuters, which regularly indexes data on articles in about 10,000 journals published worldwide. Within the last decade or so, India has seen a substantial and recent growth in its annual output of scientific publications. Figure 1, covering 1998 to 2007, charts the increase in the number of Thomson Reuters indexed papers bearing atleast one author address in India. From an essentially flat line between 1998 and 2000, the quantity of publication outputs begins rising steadily, increasing from roughly 16,500 papers in 1998 to nearly 30,000 in 2007. he rise is even more impressive given that, in 1981, India accounted for just above 14,000 papers in the Thomson Reuters database.

The 2007 total constitutes an increase of roughly $80 \%$ in seven years from 2000. Nonetheless, the absolute volume for India is still only about half that for countries such as the UK, Germany, China or Japan. This is a surprise given the capacity of its economy. It has typically taken a $2.5 \%$, now rising to $3 \%$, share of world outputs. India's recent increase is striking, rising sharply in contrast to the other nations' largely static changes in growth since 2000 .

However, what many observers may note is the change in trajectory for India. Compared to other nations with a major research base it did indeed slumber-deeply through the 1980s and only starting to awaken in the 1990s If this trajectory continues then India's productivity will be on a par with most G8 nations within 78 years and overtake them between 2015-2020. n a recent five-year period, India produced roughly 126,000 papers, constituting $2.75 \%$ of the world's papers published in journals indexed by Thomson Reuters.

Here we examine how that share panned out across different subject areas. India's strength — as a share of total world activity — proves to be diverse, with Chemistry predominant for the most recent five-year period. It is followed closely by Agricultural Sciences, but agriculture has fallen back relative to the earlier period while Pharmacology has expanded rapidly. In fact, India's portfolio is markedly balanced between the life sciences and physical sciences.

\section{Shortcomings of Research and Publication:}

1.Research facilities are unavailable 2. Research funds are unavailable 3. Industrial research fails to generate conducive atmosphere for academic research. 4. The complete education system, right from primary schooling is crazy behind marks, making education and research more objective and less subjective and hence less elaborate. 5. When a child asking 'WHY?' punished in the class, his research aptitude gets killed. Revamping of the whole education system requires us to hire not just good professors but also good teachers and make the intelligent minds a part of the system. 
Every research initiative usually requires extensive investment - and the rewards of such an investment are usually minuscule or long term oriented. India may never yield sufficient dividends hence the natural lack of research is understandable. But, if universities in India, like their Chinese counterparts, connect research quantity (output) for tier A+ submission to known journals with employment it will all work out. Like in China, only employ professors who have an excellent publishing record - pay them extremely well, benchmarking the private sector, but have very high evaluation standards and everything will fall in place. You have to pay them very well to ensure quality researchers are attracted, likewise, you have to ensure extreme standards by imposing rigid employment retention requisites.

we have certainly lagged behind the Chinese in recent times in developing research infrastructure to be at par with the West. Unfortunately it is due to a combination of factors including lack of adequate experienced faculty, unhealthy practices of the existing ones (I have seen faculty getting the student to prepare articles and submitting it without even acknowledging the student), lack of long-term vision from the administration, funding

Merely allotting more funds is not going to improve the situation. That would only benefit the managements of the private institutions not those who pursue research. In the survey conducted by the UGC shows that a quarter of the faculty in Indian higher education institutions spends less than five hours per week on research. This is because the teaching staff of most private institutions are overloaded with academic and non academic works, they can hardly spend time in any research. Most institutions don't even follow the UGC/AICTE's recommended teaching hours. The pay structure is not ample to attract bright minds. Just forcing or compelling existing staff to produce research publications is not going to be a prolific idea.

The pressure to publish-or-perish also detracts from the time and effort professors can devote to teaching undergraduate (and some graduate) courses. The rewards for exceptional teaching rarely match the rewards for exceptional research, which encourages faculty to favour the latter whenever they conflict.

Many universities do not focus on teaching ability when they hire new faculty, and simply look at the publications list (and, especially in technology-related areas), the ability to bring in research money. This singleminded focus on the professor-as-researcher may cause faculty to neglect or be unable to perform some other responsibilities.

Teaching in colleges is marked by historic paradox: though institutions constantly talk up its importance, they evaluate faculty primarily on the basis of scholarly achievements outside the classroom. Teaching is what almost every professor does, but it seems to suffer from that very commonness. It occupies the greatest amount of most professors' time, but rarely operates at the highest level of competence.

Today, there is virtually endemic dissatisfaction with the faculty reward system. The typical system overvalues research and scholarship and programs. At bottom, the values predominant in higher education generally do not support teaching.

\section{Challenges of Research and Publication:}

What are the defining requirements to create and continue a value-added Research or Comprehensive university? What is our vision? What is the objective for the University? For research? For programs? For curriculum? What is required for each to conduct useful continuous improvement - to be a "learning university."

A "learning university" (based, in part, on Senge, 1990 and on Lick \& Kaufman, 2000) is one where everyone in it understands and acts on the basis that (1) the world is ever-changing, (2) individual skills, knowledges, attitudes, and abilities will also have to change, sometimes dramatically during the course of experiences and the personal and occupational life of each person, (3) change must be based on adding value to all internal and external partners, (4) information and learning opportunities are equally available to everyone who can qualify for entry regardless of color, race, creed, sex, age, religion, national origin, or location, (5) research provides the basic knowledge for the continuous improvement of our society and citizens and is a primary source of economic and social renewal. A learning organization, including a university (cf. Senge, 1990), is vital to societal, international, national and local interest. Without ever- improving our abilities and responsiveness, it cannot hope to stay nationally and internationally competitive and remain major players and contributors in terms of social and commercial concerns and opportunities.

Several major challenges face higher education as it attempts to serve well and well serve its clients both within the university context and beyond.

\section{Among the challenges will be identifying research and teaching/learning elements:}

What research should be accomplished and why?

What are the basic elements of a useful program of research and development?

Who are the primary and secondary clients for research?

What will be the societal spin-offs for research?

What will be the University benefits of the conducted research? 
What will be the return-on-investment for funding agencies and their clients?

What data are collected and used for continuous improvement?

\section{Identifying the Mission for a Research:}

For a generic mission objective or a research or comprehensive university. It links to an Ideal Visionthe measurable statement of the kind of world we commit to create for tomorrow's child -- for not the university alone but to adding value, measurable, to society.

The utility of research discoveries often appears much later when others have extended the discovery into related areas of research, broadening the significance, and developing a full understanding that transforms the original invention into products or processes that change the way we live, create substantial economic or social value, or provide a major national competitive advantage.

The task of building and sustaining an American research university challenges every member of the institution's extended community. Progress in this permanent quest requires enthusiasm, commitment, talent, and resources, but it also requires reliable comparative data. The task for universities is to improve, not only measured by what they did last year or the year before, but also in comparison to what their counterparts and competitors at other universities have accomplished.

\section{How to improve Publication and research quality in India and World?}

It's a well established fact that India is going downhill in science education and research, despite of relative huge increase in funding and being the major technical manpower supplier for IT and global research community, successfully undertaking Moon mission and so on. I am wondering how we can regain our lost glory and improve on that so far our science education and research is concerned. I am mentioning some remedies below that came to my mind.

Reduce spending of public money on higher education and research for non-performing institutes and universities. Only teaching (without any productive research in form of quality publications or usable patents) does not justify huge spending by some so-called "elite" institutes/universities. All institutes/universities should be graded and judged as per their performance and public monetary support should depend on that. (UGC has started this but not with much cooperation from universities and so-called elite institutes and with very limited success so far).

Introduce strict accountability of public money for any research in any institute or university. And any research finding (mainly related to novel service or product) using public money must be mentioned in an open source (e.g unrestricted web site(s) for public access). If hundreds of corers of rupees are spent on "developing Bt- crop for insect resistance", then public have the right to know what is the outcome from that huge spending of tax payers' money. And if needed, a farmer or other researcher(s) should be able to access that information and more importantly the materials developed in such projects, as claimed by the researcher/institute.

Private institutes and universities must follow a minimum standard to give degrees.

Start "tenure track" system in Indian institutes/universities.

Increase spending substantially on primary and high school education (Both qualitative and quantitative). Increase the salaries of teachers at least at par with university lecturers and put stringent quality control while recruiting the teachers and introduce accountability among them. We must increase substantially the number of primary schools and quality of those and improve on physical infrastructures like school buildings, a minimum standard of school laboratory and library, a decent play ground, some internet connected computers in libraries etc.

Change the education system from the primary level (reduce work load, put more importance on physical activities, encourage original thinking etc). There should not be any form of evaluation (exam or so) till age 10 years (i.e till class 4 level). Subsequently the exam patterns should change and put more emphasis on original thinking and problem solving rather than emphasizing database-quiz type format. Basic education should be in mother tongue but English also should be compulsory from class 1.

Provide increased opportunities for students in rural and semi-urban India (in form of transparent information dissemination, transparent selection for fellowship/scholarships and recruitments).

We need to create the conducive environment for people to enthusiastically involve in research.

Improving quality and providing more funds to state universities will be the focus of India's higher education policy in the coming year. Unprecedented countrywide expansion in higher education institutions has been the priority for the past two years. But with infrastructure and recruitment of talented faculty unable to keep up with growth, the emphasis in 2012 - coinciding with the beginning of India's 12th Five Year Plan - will be on strengthening new and established institutions, particularly their quality. Quality is also key to enhancing partnerships with international institutions and preparing for the entry of foreign branch campuses once the much-delayed Foreign Educational Institutions Bill clears parliament, as expected this year. 


\section{Conclusion:}

Looking into the advantages associated with research over disadvantages, we can conclude that research should be mandatory for teachers who are guides or prospective guides and research publications should be one of the requirements for promotion.

Research provides an important learning activity. With some effort, problems faced by teachers and students can be minimized and research output can be improved. To make research a useful and enjoyable exercise, there is a need to change the attitude of students as well as teachers. It is a waste of time trying to reinvent the wheel. Literature should be searched to have an idea on what is already known and how their research will add to current knowledge. Impact and benefits refers to the contribution of research outcomes for society, culture, the environment and/or the economy.

Research must provide the knowledge base for the health, well-being, survival, and self-sufficiency for all. If either research or a research or comprehensive university does not add value to society it is probably not worth doing or having. So, an Ideal Vision is a common and shared "guiding star" toward which all partners, including researchers, faculty, students, administrators, funders, and boards may move and uniquely contribute.

\section{References:}

[1] Gogolin, I. (2010) European Educational Research Quality Indicators (EERQI): State-of-the-Art Report. Available at http://www.eerqi.eu/sites/default/files/EERQI\%20state-of-the-art\%20reportdecember\%202010.pdf

[2] Allen Consulting Group 2004, International comparison of research quality in the New Zealand tertiary education system: Discussion Paper. Retrieved 11 February 2005,from http://www.allenconsult.com.au/nztec/

[3] Allen Consulting Group 2005, Measuring the Impact of Publicly Funded Research, A report to the Department of Education Science $\begin{array}{llll}\text { and } & \text { Training. } & \text { Retrieved } & \text { May2005 from }\end{array}$ http://www.dest.gov.au/sectors/research_sector/policies_issues_reviews/key_issues/research_quality_framework/publications.htm

[4] Andrews, L., Aungles, P., Baker, S., \& Sarris, A. 1998, Characteristics and Performance of Higher Education Institutions (a preliminary investigation). Canberra: Research Branch, Higher Education Division, DETYA.

[5] Ashworth, A., \& Harvey, R. 1994, Assessing Quality in Further and Higher Education, London: Jessica Kingsley.

[6] Australian Government. 2004, 'Quality and accessibility frameworks for publicly funded research', Backing Australia's Ability: Building Our Future through Science and Innovation. Retrieved 10 February 2005, from http://backingaus.innovation.gov.au/2004/research/qual_pub_res.htm Australian National University (ANU) 2003, 'Research and research training management report', Research Office Research Data. Retrieved 14 February 2005, from http://www.anu.edu.au/ro/data/index.php

[7] Australian Research Council (ARC). 2003, 'Implementation plan for national research priorities', ARC Publications. Retrieved 17 March 2005, from http://www.arc.gov.au/publications/arc publications.htm\#priorities Australian Science and Technology Council (ATSEC) 1989, Profile of Australian Science: A study of the current state and potential of basic scientific research. Canberra: Australian Government Publishing Service. Australian Vice-Chancellors Committee (AVCC) 2003, 'Evaluation of the knowledge and innovation reforms: AVCC submission', Submission to Reviews \& Inquiries 2003 Retrieved 11 March 2005, from http://www.avcc.edu.au/documents/publications/stats/Research.pdf Australian Vice-Chancellors Committee (AVCC) 2005, 'Higher education research data collection time-series data 1992-2003', Research. Retrieved 14 February 2005, from http://www.avcc.edu.au/content.asp?page=/publications/stats/research.htm

[8] AVCC/ACDP Working Party 1988, Performance Indicators. Canberra: Australian Vice Chancellors Committee.

[9] Ball, R., \& Wilkinson, R. 1994, 'The use and abuse of performance indicators in UK higher education', Higher Education, 27, 417427 .

[10] Bird, S. M., Cox, D., Farewell, V. T., Goldstein, H., Holt, T., \& Smith, P. C. 2005,'Performance indicators: Good, bad, and ugly', Journal of the Royal Statistical Society Series A, 168(1), 1-27.

[11] Bond University 2003, Evaluation of the knowledge and innovation reforms reviewing Australia's block research funding scheme executive summary. Retrieved 10 February 2005, from http://www.dest.gov.au/highered/ki_reforms/submissions/pdf/k20.pdf | 36 Performance indicators for assessing and benchmarking research capacity in universities

[12] Bordons, M., Fernandez, M. T., \& Gomez, I. 2002, 'Advantages and limitations in the use of impact factor measures for the assessment of research performance', Scientometrics, 53(2), 195-206.

[13] Bourke, P., \& Martin, B. 1992, 'Research: Gauging the width', Australian Campus Review Weekly, August 6-12, 11-12.

[14] Brennan, J. 1990, Quality assessment in the public sector in Great Britain. In L. C. J. Goedegebuure, P. A. M. Maassen \& D. F. Westerheijen (Eds.), Peer Review and Performance Indicators (pp. 103-112). Utrecht: Lemma.

[15] Carotenuto, G., Lapegna, M., Zollo, G., Donato, A. D., \& Nicolais, L. 2001, 'Evaluating research performance: The strategy of the University of Naples Federico II (Italy)',Higher Education Policy, 14, 75-90.

[16] Cave, M., Hanney, S., \& Kogan, M. 1991, The Use of Performance Indicators in Higher Education (2 ed.). London: Jessica Kingsley.

[17] Cave, M., Hanney, S., Kogan, M., \& Trevett, G. 1988, The Use of Performance Indicators in Higher Education: A critical analysis of developing practice. London: Jessica Kingsley Publishers.

[18] Cave, M., Kogan, M., \& Hanney, S. 1990, The scope and effects of performance measurement in British higher education. In F. J. R. C. Dochy, M. S. R. Segers \& W. H. F. W. Wynand (Eds.), Management Information and Performance Indicators in Higher Education (pp. 47-58). Maastricht: Van Gorcum.

[19] Charles, D., \& Benneworth, P. 2002, 'Evaluating the regional contribution of an HEI: A benchmarking approach', Publications 2002. Retrieved 11 March 2004, from http://www.hefce.ac.uk/Pubs/hefce/2002/02_23.htm

[20] Chubin, D. E., \& Hackett, E. J. 1990, Peerless Science: Peer Review and U.S. Science Policy. New York: SUNY Press.

[21] Lee, Kirby P.; Schotland, Marieka; Bacchetti, Peter; Bero, Lisa A. (2002): Association of Journal Quality Indicators with Methodological Quality of Clinical Research Articles. JAMA (2002) 287: 2805-2808; Butler,Linda (2006); Bibliometrics and Research Performance Framework Indicators Forum Presentation with Notes) University of New South Wales, 1 May 2006. http://www.caul.edu.au/meetings/rqf2006performanceindicators. 2. pdf http://www.eurocris.org:8080/lenya/euroCRIS/live/index.html. Development of CERIF was funded by the EC and originally part of the CORDIS information platform. Why is Research and Publication necessary? 
[23] www.topuniversities.com

[24] www.timeshighereducation.co.uk

[25] admin-apps.webofknowledge.com/JCR/JCR

[26] www.esf.org/research-areas/humanities

[27] www.webofknowledge.com

[28] www.wipo.int/ipstats

[29] www.forbes.com/global2000 